\title{
Professoras que ensinam matemática nos anos iniciais e a sua formação
}

\author{
Anemari Roesler Luersen Vieira Lopes \\ Diaine Susara Garcez da Silva \\ Halana Garcez Borowsky Vaz \\ Laura Pippi Fraga \\ Universidade Federal de Santa Maria
}

\section{Resumo}

0 artigo apresenta uma pesquisa realizada com professores dos anos iniciais do ensino fundamental que investigou quais as percepções que eles têm sobre a sua formação, no que diz respeito à educação matemática, visando discutir possíveis implicações destas percepções. Participaram do estudo cinquenta professores da rede pública municipal de Santa Maria, RS, que responderam a um questionário, cuja interpretação foi orientada pela análise de conteúdo. Os resultados apontam para a necessidade de discutir-se, de forma mais aprimorada, a formação oferecida pelas disciplinas curriculares relativas à educação matemática nos cursos de formação de professores que ensinam matemática nos anos iniciais.

Palavras-chave: Educação matemática nos anos iniciais. Formação de professores. Práticas docentes. 


\section{Teachers who teach mathematics in early elementary school and their training}

This article presents a survey conducted early elementary school teachers, investigating their perceptions about their training, specifically their mathematics education, in order to discuss possible implications of these perceptions. The study included fifty teachers from municipal public schools in the city of Santa Maria, who answered a questionnaire, the interpretation of which was guided by content analysis. The results point the need to discuss more adequately the training offered by the mathematics subjects in the curriculum of teachers education courses for teachers who teach mathematics in early elementary schools.

Keywords: Mathematics education in early elementary school. Teacher training. Teaching practices.

\section{Profesoras que enseñan matemática en los años iniciales y su formación}

El artículo presenta una investigación realizada con profesores de los años iniciales de la enseñanza primaria que buscó cuáles son las percepciones que ellos tienen sobre su formación en lo que se refiere a la educación matemática, apuntando a discutir posibles implicaciones de estas percepciones. Participaron del estudio cincuenta profesores de la red pública de la ciudad de Santa Maria (RS), que respondieron a un cuestionario, cuya interpretación fue orientada por análisis de contenido. Los resultados arrojaron la necesidad de discutirse, de modo más esforzado, la formación ofrecida por las asignaturas curriculares relativas a la educación matemática en las carreras de formación de profesores que enseñan matemática en los años iniciales.

Palabras clave: Educación matemática en los años iniciales. Formación de profesores. Prácticas docentes. 


\section{Introdução}

A preocupação com a educação matemática vem acompanhando nossa trajetória de professoras e pesquisadoras. Tal fato tem sido recorrente, em especial, nos últimos anos, na condição de participantes de um grupo de estudos e pesquisas em que temos voltado a nossa atenção às questões ligadas ao ensino e à aprendizagem, assim como à formação de professores que ensinam matemática nos anos iniciais do ensino fundamental.

A motivação para este direcionamento é determinada por uma situação que poderíamos chamar de adversa. Por um lado, evidenciamos o avanço do interesse e das pesquisas nesta área, principalmente quando constatamos que eventos científicos tradicionais da educação matemática, como o Encontro Nacional de Educação Matemática (ENEM), o Simpósio Internacional de Pesquisa em Educação Matemática (SIPEM), a Conferência Interamericana de Educação Matemática (CIAEM), entre outros, vêm organizando grupos de trabalho específicos voltados aos anos iniciais. Por outro lado, as produções ainda são escassas, e compreendemos que muitas questões em relação ao processo de ensino e aprendizagem, além da formação dos professores que ensinam matemática nos anos iniciais do ensino fundamental, merecem maior atenção por parte dos pesquisadores.

Estas constatações provocaram-nos a necessidade de conhecer um pouco melhor os professores que atuam neste segmento de ensino. Pautados na ideia de que as concepções dos professores - crenças, visões e preferências - desempenham um papel importante na sua prática docente (Thompson, 1997), resolvemos dar-lhes voz para que pudéssemos compreender o que eles pensam sobre o ensino e sobre a sua formação. Assim, desenvolvemos, ao longo de 2009 e 2010, uma pesquisa que abordou questões sobre a matemática, o ensino de matemática nos anos iniciais e a formação dos professores deste nível. Para isso, foi elaborado um questionário composto por dezesseis perguntas abertas e fechadas, direcionado a professores das escolas municipais da cidade de Santa Maria, situada na região central do Rio Grande do Sul - RS.

Levando em consideração que essa rede municipal conta com quarenta e oito escolas na zona urbana, e na impossibilidade de investigar todas, foi delimitada uma amostra composta por quatorze escolas, determinadas por sorteio, o que significou um número próximo a vinte e cinco por cento de cada uma das cinco regiões que constituem a cidade. Todos os cento e dez professores destas escolas foram convidados a participar da pesquisa. Obtivemos a colaboração de cinquenta deles, que responderam ao questionário após ler e assinar o Termo de Consentimento Livre e Esclarecido, garantindo-lhes a obediência aos critérios éticos determinados pelo Comitê de Ética 
em Pesquisa da instituição onde o estudo foi empreendido'. Por isso, em alguns momentos da análise dos dados em que apresentamos excertos das respostas, os autores foram identificados pela palavra Professora - por serem todas do sexo feminino - seguida de um número de 1 a 50 , que foi atribuído aleatoriamente.

Especificamente neste artigo, o nosso objetivo é discutir o que pensam os professores sobre a sua formação, visando ainda refletir acerca de possíveis implicações destas percepções. Por isto, elencamos somente as seis perguntas iniciais do questionário citado, considerando que estas contemplam o objetivo proposto. Para a organização e a análise das respostas dissertativas decorrentes das perguntas que solicitavam aos professores que argumentassem as suas opções, utilizamos a análise de conteúdo baseada em Bardin (2002), cujas categorias emanadas da organização das respostas foram dispostas em quadros. Assim sendo, diante do exposto, iniciamos o artigo com uma breve apresentação acerca de algumas questões que julgamos pertinentes sobre a formação de professores para os anos iniciais e as pesquisas sobre este tema. Posteriormente, trazemos os dados obtidos nos questionários e finalizamos com algumas considerações sobre eles.

\section{Sobre a formação dos professores que ensinam matemática nos anos iniciais}

A matemática, enquanto disciplina escolar, é permeada por uma série de crenças que influenciam, de maneira considerável, o ensino por parte do professor e a aprendizagem por parte dos alunos. Parece haver um consenso tácito de que é uma das áreas mais difíceis do currículo da educação básica.

Ao nos referirmos aos professores que ensinam matemática nos anos iniciais, lembramos que eles vivenciaram essa realidade desde o início de sua escolarização, o que pode significar onze anos em que a matemática fez parte do currículo por eles estudado. De acordo com Nacarato, Mengali e Passos (2009), vários autores têm apontado que professores são influenciados por modelos de docentes que conviveram desde os anos iniciais e que a sua formação profissional já estava sendo desenvolvida desde então. Dentre esses autores, destacamos Thompson (1997), que, ao procurar entender o relacionamento existente entre a prática de sala de aula e as crenças dos professores de matemática, verificou que as concepções tidas por eles quanto à natureza da matemática, da aprendizagem e das habilidades de seus alunos eram fundamentais na prática de sala de aula.

1. A coleta e a organização inicial dos dados contaram com a colaboração da acadêmica do curso de pedagogia Amanda de Cassia Borges Ribeiro, da Universidade Federal de Santa Maria, bolsista do Fundo de Incentivo à Pesquisa FIPE/UFSM, órgão financiador da pesquisa. 
Estudos como estes nos levam a supor que os anos de escolarização básica tendem a contribuir para a criação e a manutenção de imagens e mitos sobre a matemática e o seu ensino. Nesta perspectiva, a história de vida e a trajetória profissional podem ser tomadas como referência para a organização das disciplinas curriculares nos cursos de formação de professores ou futuros professores. Especificamente em matemática, isto contribuiria para que possíveis imagens ou mitos negativos sejam trabalhados e, como consequência, desenvolvam-se atitudes positivas em relação a esta disciplina que, de acordo com Gonzales e Brito (1996), podem influenciar favoravelmente a aprendizagem do aluno.

Em se tratando da disciplina de matemática do curso de pedagogia - licenciatura que forma professores para os anos iniciais -, é importante que se reflita em que medida ela se constitui como uma real oportunidade para que futuros docentes possam apropriar-se dos conhecimentos matemáticos básicos que muitos não tiveram a oportunidade de aprender na educação básica, mas que terão que ensinar na condição de professor. Esta questão merece um olhar mais apurado, uma vez que, assim como explicam Nacarato, Mengali e Passos (2009), as futuras professoras dos anos iniciais têm tido poucas oportunidades para uma formação matemática que possa fazer frente às atuais exigências da sociedade. E quando isso ocorre na formação inicial, o enfoque concentra-se quase que exclusivamente nos aspectos metodológicos.

A discussão da matemática do ponto de vista metodológico é extremamente importante e deve estar relacionada às possibilidades de reflexão sobre a ação docente. Contudo, não se pode restringir esta abordagem a um agrupamento, de forma estanque, de determinadas práticas de sala de aula sob o rótulo de boas e más, positivas e negativas, tradicionais e alternativas. Evidentemente, existem algumas práticas mais favoráveis para a aprendizagem do aluno, sendo as mais interessantes aquelas que levam à discussão, à reflexão, à descoberta, propiciando a integração e o estabelecimento de relações entre os diversos conceitos matemáticos (Magina; Spinillo, 2004).

Ao realizar uma pesquisa sobre como os cursos de formação dos professores dos anos iniciais contemplam a matemática, Curi (2005) verificou que, historicamente, não se deu a atenção necessária à construção dos conhecimentos matemáticos para ensinar, mas à maneira mecânica de repetir sempre da mesma forma o ensino. A autora lembra que os professores especialistas das áreas de conhecimento dos anos finais do ensino fundamental e do ensino médio devem ensinar com preocupações como a aprendizagem de seus alunos, as dificuldades apresentadas, as metodologias que podem aprimorar a sua prática em sala de aula relativas especificamente a sua disciplina. No entanto, os professores que atuam nos anos iniciais possuem demandas diferenciadas, uma vez que precisam trabalhar com todas as áreas do conhecimento, sendo necessário que saibam os conteúdos para poder ensiná-los aos educandos. 
0 desafio para a formação inicial do professor deste segmento de ensino está, de acordo com Nacarato, Mengali e Passos (2009), em criar contextos para a apropriação dos fundamentos da matemática de forma integrada às questões pedagógicas. No que diz respeito à formação continuada, esta centra-se na superação de propostas de cursos pautados apenas em sugestões de novas abordagens para a sala de aula, que em nada têm contribuído para a formação profissional docente. Neste sentido, há de se pensar em uma formação que viabilize a compreensão dos conceitos teóricos articulados aos metodológicos. Isto implica a necessidade da contribuição de pesquisas, uma vez que diversas questões relacionadas a esta possível articulação merecem análises aprimoradas.

Lembramos que a educação matemática vem fortalecendo-se nos últimos anos na sua condição de campo não só profissional mas também científico (Fiorentini; Lorenzato, 2006), e, como correlato, o desenvolvimento de pesquisas vem aumentando. Contudo, as investigações sobre educação matemática nos anos iniciais do ensino fundamental são relativamente recentes e poucas. Nacarato e Paiva (2008) realizaram um estudo no GT 07 (grupo de trabalho 07: Formação de Professores que ensinam matemátical da Sociedade Brasileira de Educação Matemática (SBEM), buscando tendências das pesquisas apresentadas nesse grupo, de 2003 a 2008. Entre as suas conclusões, uma das constatações apontadas é a pouca atenção que pesquisadores têm dado à formação matemática do professor que atua na educação infantil e nos anos iniciais do ensino fundamental, identificando um número bem reduzido de trabalhos.

Compartilhando das mesmas preocupações dessas autoras, realizamos uma busca nos anais das reuniões da Associação Nacional de Pós-Graduação e Pesquisa em Educação - ANPEd e no Banco de Teses da Coordenação de Aperfeiçoamento de Pessoal de Nível Superior - Capes.

No estudo realizado nos anais da ANPEd, foram mapeados os trabalhos ${ }^{2}$ apresentados entre a $23^{\mathrm{a}}$ e a $33^{\mathrm{a}}$ reunião nos grupos Formação de Professores (GT-08) e educação matemática (GT-19), que enfocavam os temas relativos à formação de professores dos anos iniciais do ensino fundamental e Educação Matemática neste nível de ensino. Constatamos que, entre os duzentos e quarenta e três trabalhos do GT Formação de Professores - trabalhos apresentados no período citado -, dezoito (menos de $8 \%$ ) abordaram a formação dos professores dos anos iniciais no ensino fundamental, dando maior ênfase às questões relacionadas ao curso de pedagogia. No entanto,

2. Neste estudo, foram analisados somente os artigos apresentados na modalidade de "trabalho", não incluindo os "pôsteres". 
nenhum mencionou o ensino de matemática. Por sua vez, dos cento e setenta e um artigos do GT Educação Matemática, apenas treze (menos de $8 \%$ ) tratavam sobre a matemática nos anos iniciais. Entre as temáticas encontradas nestes últimos, estão: organização de dados; formação de professores que ensinam matemática nos anos iniciais; formação de professores e as aulas de matemática no curso de pedagogia; ensino de geometria; resolução de problemas aditivos; resolução de problemas de divisão não exata; tarefas investigativas no ensino de matemática; estudos sobre o campo conceitual aditivo nos anos inicias. Embora envolvessem essa diversidade de temas, nove dos trabalhos focavam mais especificamente o processo de ensino e aprendizagem da matemática nos anos iniciais, e quatro destes apresentavam pesquisas com a preocupação voltada à formação dos professores que ensinam matemática do $1^{\circ}$ ao $5^{\mathrm{a}}$ ano do ensino fundamental.

No banco de teses da Capes, buscamos, na área de "Educação", pesquisas realizadas entre os anos de 2000 e 2010 relacionadas à "educação matemática", cujos números estão apresentados no Quadro 1.

\section{Quadro 1 - Pesquisas sobre educação matemática}

\begin{tabular}{|c|c|c|c|}
\hline Ano & Dissertações & Teses & Total \\
\hline 2000 & 58 & 16 & 74 \\
\hline 2001 & 66 & 16 & 82 \\
\hline 2002 & 85 & 15 & 100 \\
\hline 2003 & 104 & 29 & 133 \\
\hline 2004 & 135 & 21 & 156 \\
\hline 2005 & 157 & 27 & 184 \\
\hline 2006 & 148 & 37 & 185 \\
\hline 2007 & 169 & 41 & 210 \\
\hline 2008 & 174 & 51 & 225 \\
\hline 2009 & 212 & 50 & 262 \\
\hline 2010 & 203 & 54 & 257 \\
\hline Total & $\mathbf{1 . 5 1 1}$ & $\mathbf{3 5 7}$ & $\mathbf{1 . 8 6 8}$ \\
\hline
\end{tabular}

Fonte: Banco de Teses da Capes.

Posteriormente, fizemos um refinamento na pesquisa, investigando os dados a partir da expressão "educação matemática nos anos iniciais", sendo o resultado apresentado no Quadro 2. 
Quadro 2 - Pesquisas sobre educação matemática nos anos iniciais

\begin{tabular}{|c|c|c|c|c|c|c|c|}
\hline \multirow{2}{*}{ Ano } & \multicolumn{2}{|c|}{$\begin{array}{l}\text { Formação de } \\
\text { Professores }\end{array}$} & \multicolumn{2}{|c|}{$\begin{array}{c}\text { Processos de Ensino } \\
\text { e Aprendizagem }\end{array}$} & \multicolumn{2}{|c|}{ Outros } & \multirow{2}{*}{ Total } \\
\hline & Dissertações & Teses & Dissertações & Teses & Dissertações & Teses & \\
\hline 2000 & - & - & - & - & - & - & - \\
\hline 2001 & 1 & - & - & - & - & - & 1 \\
\hline 2002 & 1 & - & 1 & - & - & - & 2 \\
\hline 2003 & - & - & 3 & - & 1 & - & 4 \\
\hline 2004 & 2 & - & 1 & - & 1 & - & 4 \\
\hline 2005 & 1 & 1 & 2 & - & 2 & - & 6 \\
\hline 2006 & - & - & 1 & - & - & - & 1 \\
\hline 2007 & 4 & 1 & 2 & - & 2 & 1 & 10 \\
\hline 2008 & 3 & 1 & - & 3 & 1 & 1 & 09 \\
\hline 2009 & 7 & 3 & 5 & 1 & 2 & - & 18 \\
\hline 2010 & 9 & 1 & 4 & - & - & 1 & 15 \\
\hline Total & 28 & 7 & 19 & 4 & 9 & 3 & 70 \\
\hline
\end{tabular}

Fonte: Banco de Teses da Capes.

Da análise destes dados, é notória a constatação de que, nos últimos anos, o número de teses e dissertações sobre os temas citados aumentou consideravelmente. Em números absolutos, a quantidade de produções em educação matemática passou de setenta e quatro para duzentas e cinquenta e sete (um aumento de $347 \%$ ); e especificamente relacionada aos anos iniciais, de nenhuma para quinze. Contudo, na comparação entre os quadros, verificamos que, no período considerado, de todas as mil, oitocentas e sessenta e oito pesquisas em educação matemática, somente setenta estavam relacionadas aos anos iniciais do ensino fundamental (quase $4 \%$ ). Se observarmos 0 ano de 2010 , esse percentual aumenta em torno de $6 \%$, mas ainda não é significativo. Ou seja, por mais que os estudos estejam aumentando, ainda são um número reduzido.

Com o intuito de contribuir e, principalmente, ampliar as discussões sobre a educação matemática nos anos iniciais, apresentamos os resultados de nossa pesquisa sobre 0 olhar que professores deste nível de ensino têm a respeito da sua formação. 


\section{Sobre o que pensam as professoras}

Como já citado, os sujeitos da pesquisa eram todos do sexo feminino. Com o intuito de melhor conhecê-los, solicitamos que fornecessem alguns dados gerais sobre a sua formação. Foi possível constatar que quarenta e oito professoras $(96 \%)$ possuem curso superior, sendo que vinte e sete (56\%) são formadas em pedagogia e vinte e uma (44\%) possuem graduação em outras licenciaturas como letras, geografia, química, biologia, educação física e estudos sociais.

0 alto índice de formação em nível superior pressupõe um aspecto a ser considerado positivo, embora seja relevante ressaltar que só pouco mais da metade das docentes tem a formação específica para os anos iniciais do ensino fundamental. Essa situação pode encontrar justificativa no plano de carreira do magistério público municipal de Santa Maria, que estabelecia o curso de magistério em nível médio como formação mínima para o exercício docente nos anos iniciais e permitia o avanço na carreira com um curso de licenciatura, mas sem a exigência de que fosse pedagogia. Atualmente, visando a atender a Lei de Diretrizes e Bases da Educação - LDB, Lei no 9.394/1996 (Brasil, 1996), o ingresso na carreira para este nível de ensino só é permitido com a habilitação específica em pedagogia, mas, para os professores já efetivos com formação em nível médio, ainda é viabilizado o acesso mediante qualquer curso de licenciatura.

Por um lado, não há como negar que a perspectiva de ter um docente com curso superior atuando em sala de aula atribui um caráter diferenciado ao ensino que, pressupõem-se, será de melhor qualidade. Por outro lado, há de se considerar que a formação nas licenciaturas das áreas específicas não prepara o futuro professor para atuar nos anos iniciais, cujas características diferem profundamente das relativas aos anos finais do ensino fundamental e ensino médio. Não estamos, com isso, afirmando que um professor que não tenha curso de pedagogia não possa organizar o seu ensino de forma a contribuir significativamente para a aprendizagem do aluno. 0 que questionamos é em que medida isso pode ser generalizado.

Ainda em relação aos cursos de formação, entre as professoras que possuem nível superior, quarenta e quatro (92\%) cursaram pós-graduação em nível de especialização lato sensu, em especificidades diversas: psicopedagogia (quatorze), educação infantil (sete), alfabetização (seis), educação ambiental (cinco), supervisão escolar (três), interdisciplinaridade (dois), língua portuguesa (dois), orientação educacional, informática educacional, dança, letras e matemática. Essa parcela significativa de docentes com pós-graduação ( $88 \%$ do total de participantes da pesquisa) também é um fato relevante. Não foi possível identificar se todos os cursos frequentados tinham o enfoque direcio- 
nado aos anos iniciais, contudo, detectou-se que seis professoras, entre as vinte que fizeram curso que, à primeira vista, parece estar diretamente relacionado ao processo de ensino e aprendizagem nos anos iniciais - psicopedagogia e alfabetização -, possuíam habilitação em licenciaturas de áreas específicas. Expressando de outra forma, pode-se considerar que quase $29 \%$ das professoras que não possuem curso de pedagogia (entre as que possuem curso superior) realizaram um curso de pós-graduação lato sensu em área que contempla os anos iniciais do ensino fundamental.

Complementando, ainda, as informações iniciais sobre as professoras participantes da pesquisa, nossa primeira pergunta visou a investigar se haviam participado de algum curso de formação continuada (de vinte horas ou mais) nos dois últimos anos. Quarenta e três (86\%) responderam que sim e apontaram os enfoques dos cursos que, agrupados, estão apresentados no Quadro 3.

\section{Quadro 3 - Você participou de algum curso de formação continuada de vinte horas ou mais, nos últimos dois anos?}

\begin{tabular}{|l|c|}
\hline \multicolumn{1}{|c|}{ Enfoque } & Quantidade \\
\hline Alfabetização/Linguagem & 12 \\
\hline Matemática & 11 \\
\hline Metodologias de Ensino/Jogos & 10 \\
\hline Inclusão/Diversidade & 10 \\
\hline
\end{tabular}

Fonte: Dados da pesquisa.

Os dados organizados das respostas refletem uma realidade normalmente presente nas escolas dos anos iniciais do ensino fundamental: o principal enfoque está concentrado na língua materna, seguida da matemática (total de 53\%). E esta compreensão pode não ser exclusiva dos docentes, uma vez que devemos levar em consideração que os cursos a que se referiram as professoras nesta questão são oferecidos pela Secretaria Municipal de Educação. Além disso, o como ensinar também parece ser uma preocupação, o que é evidenciado na citação de cursos de metodologias e encaminhamentos, como a utilização de jogos (quase $24 \%$ ).

Provavelmente como decorrência de discussões contemporâneas, e mais especificamente da atual legislação, temas relacionados à inclusão e à diversidade também fizeram parte dos cursos de capacitação (frequentados por quase $24 \%$ das professoras). A inquietação sobre a inclusão de alunos com necessidades educativas especiais é destacada na pesquisa de Assis e Martinez (2011), que notaram a insatisfação dos docentes sobre como ocorre a inclusão no ambiente escolar. Nesse mesmo sentido, 
Smeha e Ferreira (2008) apontam que o professor normalmente é preparado para trabalhar com as crianças que aprendem; assim, quando ele se depara com as limitações na aprendizagem, sente frustração, angústia, impotência e medo.

$\mathrm{Na}$ expectativa de conhecer um pouco o processo de escolarização dos nossos sujeitos, mais especificamente relacionado à matemática, na segunda pergunta questionamos se lembravam de algum conteúdo desta disciplina estudado no ensino fundamental. Quarenta e seis professoras (92\%) responderam que lembravam. Destas, dezesseis não fizeram menção a conteúdos, mas usaram expressões de âmbito geral como "muitos conteúdos" ou "quase tudo", o que pode indicar que nenhum deles tenha sido marcante. As outras trinta apontaram explicitamente um ou mais termos, que foram agrupados de acordo com o conteúdo matemático que estão relacionados no Quadro 4.

\section{Quadro 4 - Você se lembra de algum conteúdo de matemática que estudou em sua vida escolar do ensino fundamental? Em caso positivo, qual?}

\begin{tabular}{|l|c|}
\hline \multicolumn{1}{|c|}{ Conteúdo } & Número de vezes citado \\
\hline Operações com números naturais & 15 \\
\hline Tabuada & 13 \\
\hline Resolução de problemas & 7 \\
\hline Expressões numéricas & 4 \\
\hline Equações & 4 \\
\hline Números fracionários & 2 \\
\hline Regra de três & 1 \\
\hline Juros & 1 \\
\hline
\end{tabular}

Fonte: Dados da pesquisa.

As maiores lembranças se referem às operações fundamentais. Esta constatação compactua com a concepção amplamente difundida de que a matemática é a ciência dos números e operações, e esta visão é expressiva para o aluno que passa pelo processo de escolarização, ainda mais se recordarmos que outros conteúdos categorizados no quadro (tabuada, resolução de problemas e expressões numéricas) estão relacionados às operações. Outro fato que coincide com essa verificação é que a geometria, que pode ser considerada como um conteúdo diferenciado, por permitir que se estabeleçam variados tipos de relações, sem necessariamente utilizar números e cálculos, não foi citada por nenhum dos sujeitos.

Segundo Grando (2009), o tempo dedicado ao ensino da geometria na educação básica tem sido reduzido - ou já está quase escasso - há mais de duas décadas. A autora 
sublinha inúmeros causadores desse abandono, sendo um deles de caráter histórico, - Movimento da Matemática Moderna, que de certa forma priorizava a álgebra e o formalismo pela linguagem. Destaca-se a referência feita à tabuada, que se constitui como a organização dos resultados da operação de multiplicação. Normalmente, não é compreendida como tal, mas como um mero processo de memorização, desvinculado da operação que a originou. Tal fato tem perpetuado a ideia de que a memorização é um requisito fundamental para o ensino da matemática, quando deveria ser entendida como um instrumento que agiliza a realização de cálculos, principalmente quando do uso de algoritmos.

Os números fracionários também foram lembrados, além de dois conteúdos que se referem especificamente aos anos finais do ensino fundamental: regra de três e juros. Isto nos leva a refletir em que medida o professor dos anos iniciais - assim como qualquer outra pessoa que possui curso de nível superior e passou por um processo de escolarização que exigiu, no mínimo, oito anos de estudos nos quais a matemática foi um dos componentes curriculares -, aparentemente apropria-se destes conhecimentos e, com o passar do tempo, na maioria das vezes, nem se recorda mais deles.

É comum nos depararmos com a ideia de que os professores dos anos iniciais não sabem matemática ou, ainda, não gostam da mesma. Contudo, questionamos: são somente os professores dos anos iniciais que não gostam ou não sabem matemática ou seria parte considerável dos alunos que ingressam no ensino superior e que não se apropriaram dos conteúdos matemáticos da educação básica? Desta questão deriva outra, mais grave: se o professor não aprendeu matemática em seu processo de escolarização básica, a sua formação inicial - licenciatura - conseguirá ensiná-lo a ensinar algo que nunca aprendeu?

A terceira pergunta direcionou-se a este enfoque, ao indagarmos se as professoras consideravam difícil ensinar matemática. Para treze delas (26\%), matemática é uma disciplina difícil de ser ensinada. Onze justificaram as suas respostas, que se encontram organizadas no Quadro 5.

\section{Quadro 5 - Porque é difícil ensinar matemática?}

\begin{tabular}{|l|c|}
\hline \multicolumn{1}{|c|}{ Justificativas } & Número de Professoras \\
\hline Relacionadas aos alunos & 5 \\
\hline Relacionadas ao conhecimento matemático & 2 \\
\hline Relacionadas ao processo de ensino & 2 \\
\hline Relacionadas à professora & 2 \\
\hline
\end{tabular}

Fonte: Dados da pesquisa. 
Podemos observar que as respostas das professoras estão relacionadas a quatro categorias: aos alunos, ao conhecimento matemático, ao processo de ensino e ao professor. Cinco delas mencionam que os alunos "em geral não prestam a devida atenção" (Professora 3), "apresentam dificuldades" (Professora 36), "se distraem com detalhes fundamentais" (Professora 47), "não querem pensar nem estudar" (Professora 27), e "não prestam atenção" (Professora 41). 0 conhecimento matemático, "por ser exato" (Professora 5) e "por sua lógica, que exige muito raciocínio" (Professora 9), foi considerado como elemento dificultador por duas professoras. 0 processo de ensino foi apontado também por duas professoras, que citaram a "falta de recursos materiais" (Professora 4) e "a falta de materiais atrativos disponíveis na escola" (Professora 9). Foram registradas, ainda, justificativas relacionadas ao professor. Dois sujeitos declararam: "sinto dificuldades" (Professora 8) e "aprendi só com memorização e não sei ensinar de outra forma" (Professora 48).

Contrariando a opinião de que é difícil ensinar matemática, trinta e sete professoras (74\%) responderam não considerar esta tarefa difícil. Este resultado pode mostrar-se como importante, uma vez que, como anotam Gonzales e Brito (1996), quando os professores demonstram atitudes positivas em relação à matemática, isto tem reflexos na sua forma de ensinar e também influencia a aprendizagem dos alunos. Justificativas para essa resposta foram apresentadas por vinte e três sujeitos e encontram-se agrupadas no Quadro 6.

\section{Quadro 6 - Por que não é difícil ensinar matemática?}

\begin{tabular}{|l|c|}
\hline \multicolumn{1}{|c|}{ Justificativas } & Número de Professoras \\
\hline Relacionadas ao processo de ensino & 14 \\
\hline Relacionadas ao conhecimento matemático & 5 \\
\hline Relacionadas ao professor & 4 \\
\hline
\end{tabular}

Fonte: Dados da pesquisa.

Os argumentos estão associados a três das quatro categorias anteriormente elencadas: ao processo de ensino; ao conhecimento matemático e ao professor. A maior parte das professoras (quatorze) relacionou a não dificuldade em ensinar matemática ao processo de ensino, por meio de argumentos como o da Professora 10: "trabalha-se com material concreto e outras atividades interessantes". Também apareceram respostas relacionadas ao conhecimento matemático, elencadas por cinco professoras, que citaram que: “a matemática faz parte do dia a dia” (Professora 21); 
“os conteúdos neste nível não são complicados" (Professora 18); "os conteúdos são concretos" (Professora 16). No que se refere ao professor, dois sujeitos declararam: "gosto de matemática" (Professora 12) e "frequento curso de matemática de formação continuada" (Professora 32).

Apesar dos resultados apresentados na pergunta anterior, ao serem indagados sobre conteúdos matemáticos que consideravam difíceis para os alunos, quarenta e oito $(96 \%)$ citaram pelo menos um item, como podemos observar no Quadro 7, que traz as respostas agrupadas de acordo com o conteúdo matemático a que se relacionam.

Quadro 7 - Você considera algum (uns) conteúdo(s) matemático(s) difícil(eis) para o aluno? Em caso positivo, qual(is)?

\begin{tabular}{|l|c|}
\hline \multicolumn{1}{|c|}{ Conteúdo } & Número de vezes citado \\
\hline Divisão & 13 \\
\hline Sistema de numeração decimal & 12 \\
\hline Números fracionários & 12 \\
\hline Números decimais & 12 \\
\hline Resolução de problemas & 10 \\
\hline Geometria & 10 \\
\hline Multiplicação & 9 \\
\hline
\end{tabular}

Fonte: Dados da pesquisa.

O conteúdo citado por mais professoras foi a operação de divisão, seguido do sistema de numeração decimal, categoria que diz respeito à organização de quantidades em ordens e classes e a representação numérica das mesmas. Os números racionais também foram considerados difíceis, tanto na sua representação fracionária quanto na sua representação decimal. Foram lembrados, além disso, a resolução de problemas (embora não seja necessariamente um conteúdo matemático), a geometria e a operação de multiplicação.

Em relação às perguntas três e quatro, duas questões chamam-nos a atenção. A primeira refere-se ao fato de que a maior parte das professoras que considera fácil ensinar matemática admite a existência de conteúdos difíceis para o aluno. Essa aparente discrepância pode evidenciar algo que não está expresso nas respostas: a concepção de que o ensinar é independente do aprender. A segunda diz respeito à vinculação que grande parte das professoras fazem da facilidade de ensinar com a 
possibilidade de uso de materiais didáticos ${ }^{3}$ diversos. A expansão da adoção dos também chamados recursos didáticos, manipuláveis ou concretos, deu-se de forma mais intensa a partir dos anos de 1980, inspirados principalmente nos trabalhos de Maria Montessori e Zoltan Dienes. Desde essa época, a defesa e os princípios teóricos do seu uso não representam uma unidade entre os educadores matemáticos.

No livro Na vida dez, na escola zero - obra que pode ser considerada como um dos clássicos dos anos de 1980, por seu enfoque voltado à aprendizagem em educação matemática -, David Carraher, Terezinha Carraher e Schilemann (1991) declaravam a sua preocupação com a utilização de recursos didáticos. Os autores afirmavam que não são os objetos em sala de aula, mas os objetivos e as situações em que a resolução de problemas implica a utilização dos princípios lógico-matemáticos a serem ensinados que levam à aprendizagem. Esta questão merece especial atenção, principalmente no sentido de que as expectativas da utilização de materiais didáticos não se concentrem na esperança de que todas as dificuldades de ensino possam ser amenizadas pelo simples suporte do mesmo. Além disso, o professor deve tomar cuidado para que a manipulação desses materiais não se restrinja a uma atividade meramente de caráter motivador, negando os valores formativos mais amplos de sua relação com os conteúdos matemáticos.

Serrazina (1990), analisando recursos materiais empregados no ensino da matemática, ressalta a dependência fundamental da competência do professor no seu uso. Este destaque remete-nos à formação do professor, uma vez que a opção pela adoção de materiais na sala de aula, desconectada de uma fundamentação teórica e de um processo de reflexão, pode conduzir a duas direções opostas: à vertente do empirismo, levando à manipulação sem a preocupação de atender objetivos de aprendizagem; ou ao racionalismo, que caracteriza os conceitos matemáticos como ideias perfeitas e abstratas. Portanto, as advertências aos materiais direcionam-se ao seu emprego alijado de reflexões que permitam ao aluno confrontar-se com situações que exijam estabelecer relações que promovam discussões, busca de soluções e formulação de novas perguntas. Os conceitos matemáticos não estão nos materiais didático-pedagógicos usados e nem tampouco deles podem ser abstraídos empiricamente. Eles serão formados pela ação interiorizada do aluno, pelo significado que dá às suas ações, às formulações que enuncia, às verificações que realiza (Passos, 2006, p. 81).

3. Tomando como referência Lorenzato (2006), fazemos uso do termo "materiais didáticos" para designar os instrumento úteis ao processo de ensino e aprendizagem, o que as professoras nomearam como "materiais concretos"; "materiais didático-pedagógicos", "recursos didáticos", "recursos materiais", sem levar em consideração as diferentes perspectivas teóricas implícitas nessas denominações, uma vez que os dados da pesquisa não possibilitam fazer tal análise. 
Revisitando ainda as duas questões anteriores, que diziam respeito às dificuldades em relação ao ensino ou aos conteúdos matemáticos, chamou-nos a atenção o fato de que nenhuma professora em suas respostas fez referência ao seu curso de formação inicial. Isto poderia ser esperado por aquelas que possuem licenciatura em áreas específicas, contudo, nem as professoras licenciadas em pedagogia citaram-na. Este fato traz fortes indícios de que a formação inicial tem pouca influência sobre as questões relativas à prática docente, e as respostas dadas à pergunta cinco podem reforçar esta compreensão. Foi solicitado às professoras que atribuíssem nota de zero a dez para a aquisição de conhecimentos que contribuíssem para desenvolver suas aulas (não necessariamente de matemática) nos seguintes espaços: o curso de formação inicial (licenciatura), a prática em sala de aula; os cursos de formação continuada (pergunta n. 4). A frequência das notas atribuídas encontra-se no Quadro 8:

\section{Quadro 8 - Número de professoras e nota atribuída à pergunta n. 4}

\begin{tabular}{|l|c|c|c|c|c|c|c|c|}
\hline \multirow{2}{*}{$\begin{array}{c}\text { Espaço de } \\
\text { Aprendizagem }\end{array}$} & \multicolumn{7}{|c|}{ Número de Professoras } \\
\cline { 2 - 9 } & Nota 4 & Nota 5 & Nota 6 & Nota 7 & Nota 8 & Nota 9 & Nota 10 & $\begin{array}{c}\text { Não } \\
\text { atribuíram } \\
\text { nota }\end{array}$ \\
\hline Formação Inicial & 6 & 3 & 5 & 2 & 11 & 1 & 15 & 7 \\
\hline A sala de aula & 1 & 1 & 0 & 0 & 8 & 10 & 23 & 7 \\
\hline $\begin{array}{l}\text { Cursos de formação } \\
\text { continuada }\end{array}$ & 5 & 3 & 2 & 0 & 13 & 8 & 14 & 5 \\
\hline
\end{tabular}

Fonte: Dados da pesquisa.

O espaço que recebeu a maior quantidade de notas máximas (valor numérico 10) foi a sala de aula, atribuída por vinte e três professoras, sendo que vinte destas são formadas em pedagogia. A maior quantidade de notas mínimas (valor numérico 4) foi para a formação inicial, conferida por seis professoras, todas formadas em pedagogia.

A valorização maior da experiência prática em relação ao curso de licenciatura também fica evidente, se levarmos em consideração que as três melhores notas (valores numéricos 8,9 e 10) foram assinaladas por quarenta e uma professoras para a sala de aula, por trinta e cinco para a formação continuada, e somente por vinte e sete para a formação inicial. Não podemos deixar de levar em consideração que parte considerável das professoras não possui habilitação específica para os anos iniciais, o que faz com que os conhecimentos da prática é que acabem, unicamente, subsidiando a sua ação pedagógica. Além disso, a vivência enquanto aluno que estudou matemática na educação básica pode constituir-se como a sua base de referência para o ensino desta disciplina (Nacarato; Mengali; Passos, 2009). 
Solicitamos, na sexta pergunta, que as professoras indicassem o que consideravam que contribuía para a sua formação docente. As respostas, agrupadas, encontram-se no Quadro 9, ressaltando-se que algumas citaram mais de um item.

\section{Quadro 9 - 0 que você considera que contribui para a sua formação docente?}

\begin{tabular}{|l|c|}
\hline \multicolumn{1}{|c|}{ Aspectos } & Número de Professoras \\
\hline Interação com os pares & 25 \\
\hline Formação continuada & 21 \\
\hline Estudos & 18 \\
\hline Orientações & 19 \\
\hline
\end{tabular}

Fonte: Dados da pesquisa.

Os aspectos mais recorrentes são concernentes ao que categorizamos como interação com os pares, e dizem respeito, nas palavras de algumas professoras, a "conversas com colegas de trabalho" (Professora 8), "troca de experiência" (Professora 34), "participação conjunta em atividades" (Professora 27). Também foi apontada a importância da formação continuada especificada como "cursos de formação" (Professora 18) e "cursos de capacitação" (Professora 40), que são normalmente oferecidos pela Secretaria Municipal de Educação, na modalidade presencial ou a distância, de curta duração (de 30 a 120 horas, em média).

Foi feito menção à importância de estudos como "leituras de livros pedagógicos" (Professora 19) e "estudos individualizados" (Professora 3), como contribuição para a formação das professoras, embora alguns tenham sido citados mais como ideais do que reais, pois o tempo não thes permite fazê-los constantemente. Ademais, orientações também foram lembradas por professoras que citaram "as recebidas da Secretaria Municipal de Educação" (Professora 25), "discutidas com as supervisoras pedagógicas da escola" (professora 37) ou, ainda, "apresentadas nos livros didáticos" (professora 44). Novamente, observamos que as professores deste estudo não elencam a formação inicial como significativamente importante para a sua formação.

\section{Considerações finais}

Conforme pudemos observar nos dados inicialmente apresentados, as investigações relativas à educação matemática nos anos iniciais vêm aumentando nos últimos tempos, embora se identifique necessidade que se ampliem e apresentem resultados que propiciem maiores discussões acerca do processo de ensino e aprendizagem neste 
segmento. Na expectativa de contribuir com este tema, buscamos neste artigo discutir sobre formação de professores, a partir do que eles pensam e das possíveis implicações destas percepções. Os dados coletados nos permitem tecer algumas considerações, das quais destacamos duas.

A primeira delas diz respeito ao fato de que a maior parte das professoras declara não considerar difícil ensinar matemática e relaciona essa facilidade à possibilidade de utilização de materiais didáticos. Essa enfática associação representa uma preocupação, na medida em que nem sempre as professoras possuem a devida clareza do papel dos materiais no processo de apropriação de conhecimentos. É inquestionável o fato de que tais recursos podem contribuir de forma significativa no processo de ensino e aprendizagem da matemática, contudo sua utilização, por si só, não conduz à aprendizagem.

Em segundo lugar, ficou evidente que as professoras, em especial as formadas em pedagogia, não demonstram estabelecer relações entre a sua formação inicial e os seus conhecimentos e possibilidades de aprendizagens para a docência. Isto foi observado mais especificamente em três momentos: quando parte notável delas afirmou não considerar difícil ensinar matemática, mas não relacionou essa afirmação a possíveis subsídios adquiridos no curso de licenciatura; quando, ao atribuírem nota para os espaços onde adquiriram conhecimentos que contribuíram para o desenvolvimento de suas aulas, deram para a formação inicial a maior quantidade de notas mínimas; e quando não fizeram menção à formação inicial como importante para a sua aprendizagem docente.

Estas duas considerações encaminham-nos a uma constatação: a necessidade de discutir-se, de forma mais aprimorada, a formação oferecida pelas disciplinas curriculares relativas à educação matemática nos cursos de pedagogia, corroborando pesquisas citadas anteriormente. Acreditamos que a formação matemática do futuro professor dos anos iniciais concerne tanto aos aspectos relativos ao conhecimento matemático quanto aos aspectos metodológicos referentes ao ensino desta disciplina. Assim, o compromisso da formação inicial é compor-se como um espaço que viabilize aos futuros professores a aprendizagem da organização do ensino, que, na visão de Moura et al. (2010), implica recorrer à articulação entre teoria e prática, como constitutiva da atividade do professor, mais especificamente a atividade de ensino. Assim, a apropriação de conhecimentos importantes para a prática docente não se resume a uma formação meramente pragmática, que ignore a teoria.

Habilitar-se para ensinar matemática nos anos iniciais implica conhecer os conteúdos a serem ensinados, bem como conhecer materiais e recursos que possam contribuir para este processo. No entanto, é preciso ficar claro que o uso destes não pode ter como objetivo facilitar os conteúdos, no sentido de superficializá-los, mas encontrar encaminhamentos para que os alunos aprendam matemática. 


\section{Referências}

ASSIS, Caroline Penteado; MARTINEZ, Cláudia Maria Simões. A inclusão escolar e utilização de tecnologia assistiva para alunos com seqüelas de mielomeningocele: opinião de professores. Revista Educação Especial, jan./abr. de 2011, n. 39, v. 24.

BARDIN, Laurence. Análise de conteúdo. Tradução de Luís Antero Reto e Augusto Pinheiro. Lisboa: Edições 70, 2002.

BRASIL. Lei de Diretrizes e Bases da Educação Nacional. Brasília, 1996.

CARRAHER David; CARRAHER, Terezinha; SCHLIEMANN, Ana Lúcia. Na vida dez, na escola zero. São Paulo: Cortez, 1991.

CURI, Edda. A Matemática e os professores dos anos iniciais. São Paulo: Musa Editora, 2005.

FIORENTINI, Dario; LORENZATO, Sérgio. Investigação em Educação Matemática: percursos teóricos e metodológicos. Campinas: Autores Associados, 2006.

GONZALES, Maria Helena; BRITO, Márcia Regina F. Atitudes (des)favoráveis com relação à matemática. Zetetiké, Campinas: CEMPEM/UNICAMP, vol. 4 (2), n. 6, p.45-63. 1996.

GRANDO, Regina Célia. Investigações geométricas na formação de professores que ensinam matemática. In: LOPES, Celi Espasadin Lopes; NACARATO, Adair Mendes. Educação Matemática, leitura e escrita: armadilhas, utopias e realidade. Campinas: Mercado das Letras, 2009, p. 201-217.

LORENZATO, Sérgio. Laboratório de ensino de matemática e materiais didáticos manipuláveis. In: LORENZATO, Sérgio (org.). O laboratório de ensino de matemática na formação de professores. Campinas, SP: Autores Associados, 2006, p. 3-38.

MAGINA, Sandra; SPINILLO, Aline Galvão. Alguns 'mitos' sobre a educação matemática e suas consequências para o ensino fundamental. In: Regina Maria Pavanello. (Org.). Matemática nas Séries Iniciais do Ensino Fundamental: A pesquisa e a sala de aula. 1 ed. São Paulo: Ed. SBEM, v. 2, 2004, p. 7-36. MOURA, Manoel Oriosvaldo et al. Atividade Orientadora de Ensino: unidade entre ensino e aprendizagem. Diálogos Educacionais, Curitiba, v. 10, n. 29, p. 205-229, jan./abr. 2010

NACARATO, Adair Mendes; MENGALI, Brenda Leme da Silva; PASSOS, Cármen Lucia Brancaglion. $A$ matemática nos anos iniciais do ensino fundamental: tecendo fios do ensinar e do aprender. Belo Horizonte: Autêntica, 2009.

. PAIVA, Maria Auxiliadora Vilela. A formação do professor que ensina matemática: estudos e perspectivas a partir das investigações realizadas pelos pesquisadores do GT 7 da SBEM. In: NACARATO, Adair Mendes; PAIVA, Maria Auxiliadora Vilela. A formação do professor que ensina Matemática: perspectivas e pesquisas. Belo Horizonte: Autêntica, 2008, p. 7-26.

PASSOS, Cármen Lucia Brancaglion. Materiais manipuláveis como recursos didáticos na formação de Professores de matemática. In: LORENZATO, Sérgio (org.). O laboratório de ensino de matemática na formação de Professoraes. Campinas, SP: Autores Associados, 2006, p. 77- 91.

SERRAZINA, Maria de Lurdes. Os materiais e o Ensino da Matemática. Revista Educação e Matemática, Lisboa, n. 13, 1990. Publicação da APM. 
SMEHA, Luciane; FERREIRA, lolete de Vlieger. Prazer e sofrimento docente nos processos de inclusão escolar. Revista Educação Especial, 2008, nº 31, v. 21

THOMPSON, Alba Gonzalez. A relação entre concepções de matemática e o ensino de matemática de professores na prática pedagógica. Zetetiké, Campinas, v.5. n. 8, p.11-44, jul./dez, 1997.

Recebido em setembro de 2011.

Aprovado em janeiro de 2012.

Anemari Roesler Luersen Vieira Lopes, doutora em Educação pela Universidade de São Paulo. Professora Adjunta do Departamento de Metodologia de Ensino do Centro de Educação e do Programa de Pós-Graduação em Educação da Universidade Federal de Santa Maria. Coordenadora do Grupo de Estudos e Pesquisas em Educação Matemática - GEPEMat. Publicação recente: LOPES, Anemari; PEREIRA, Patrícia Sandalo (orgs). Ensaios em educação matemática: algumas possibilidades para a educação básica (Campo Grande: Editora da UFMS, 2010). E-mail: anemari.lopes@ggmail.com

Diaine Susara Garcez da Silva, especialista em Planejamento e Gestão Escolar e licenciada em Pedagogia (FAFIMC). Atua como professora da Rede Pública Estadual em Santa Maria/RS e participa do Grupo de Estudos e Pesquisas em Educação Matemática - GEPEMat. Publicação recente: LOPES, Anemari; SILVA, Diaine Susara Garcez da Silva; BOROWSKY, Halana Garcez; FRAGA, Laura Pippi. 0 pastor contando suas ovelhas: uma proposta envolvendo correspondência um-a-um (In: LOPES, Anemari; PEREIRA, Patrícia Sandalo [orgs]. Ensaios em educação matemática...). E-mail: diaine_garcezQyahoo.com.br

Halana Garcez Borowsky Vaz, mestranda em Educação da Universidade Federal de Santa Maria. Atua na área de educação matemática nos anos iniciais e participa do Grupo de Estudos e Pesquisas em Educação Matemática - GEPEMat. Publicação recente: LOPES, Anemari Roesler Luersen Vieira; SILVA, Diaine Susara Garcez da Silva; BOROWSKY, Halana Garcez; FRAGA, Laura Pippi. 0 pastor contando suas ovelhas... (In: LOPES, Anemari; PEREIRA, Patrícia Sandalo [orgs]. Ensaios em educação matemática...). E-mail: halanagarcezborowskydyahoo.com.br

Laura Pippi Fraga, mestranda em Educação da Universidade Federal de Santa Maria Atua na área de educação matemática nos anos iniciais e participa do Grupo de Estudos e Pesquisas em Educação Matemática - GEPEMat. Publicação recente: LOPES, Anemari Roesler Luersen Vieira; SILVA, Diaine Susara Garcez da Silva; BOROWSKY, Halana Garcez; FRAGA, Laura Pippi. 0 pastor contando suas ovelhas... (In: LOPES, Anemari; PEREIRA, Patrícia Sandalo [orgs]. Ensaios em educação matemática...). E-mail: laurapippifragalayahoo.com.br 